\title{
Research paper: Amphetamine Type Stimulants Use in the Adult Population of Tehran: Implications for Long Term Rehabilitation
}

\author{
Hassan Rafiey ${ }^{1}$, Salahedin Ghaderi², Burzoo Morovat ${ }^{3}$, Roya Noori ${ }^{4,5}$, Mohammad Effatpanah ${ }^{6}$, Alireza Mahjoub ${ }^{7}$, Omid Massah $^{4 *}$
}

1. Social Welfare Management Research Center, University of Social Welfare and Rehabilitation Sciences, Tehran, Iran.

2. Department of Sociology, Faculty of Humanities and Social Sciences, Kharazmi University, Tehran, Iran.

3. Department of Social Sciences, Farhangian University, Tehran, Iran.

4. Substance Abuse and Dependence Research Centre, University of Social Welfare and Rehabilitation Sciences, Tehran, Iran.

5. United Nations Office on Drugs and Crime, Tehran, Iran.

6. School of Medicine, Ziaeian Hospital, International Campus, Tehran University of Medical Sciences, Tehran, Iran

7. Student Research Center, International Campus, Tehran University of Medical Sciences, Tehran, Iran.

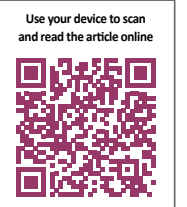

Citation: Rafiey H, Ghaderi S, Morovat B, Noori R, Effatpanah M, Mahjoub A, et al. Amphetamine Type Stimulants Use in the Adult Population of Tehran: Implications for Long Term Rehabilitation. Iranian Rehabilitation Journal. 2017; 15(4):303-308. https://doi.org/10.29252/nrip.irj.15.4.303

\section{https://doi.org/10.29252/nrip.irj.15.4.303}

Article info:

Received: 10 Mar. 2017

Accepted: 03 Jul. 2017

Keywords:

Drug, Methamphetamine, Rehabilitation, Treatment

\section{ABSTRACT}

Objectives: Dependence on Amphetamine-Type Stimulants (ATS) is a current health concern in Iran. The present study aimed to investigate the most needed treatment and rehabilitation services that a group of ATS-dependent patients in Tehran reported.

Methods: The current study is part of the first cross-sectional survey of the prevalence of ATS dependence in Tehran. A researcher-made questionnaire was used to collect data. Overall, 6027 men and women in the general adult population of Tehran were interviewed. Overall, 261 participants were ATS-dependent. Of them, 35 participants were interviewed in this qualitative study. Atlas-ti software was used for qualitative data analysis in compliance with the Grounded Theory of Strauss and Corbin.

Results: The mean age of the participants was $32(\mathrm{SD}=11)$ years (age range: $18-60$ years). The mean year of the schooling was $8(\mathrm{SD}=9)$. The content analysis of interviews showed a series of needs including rehabilitation not only treatment, brief psychosocial treatments, family education and engagement in treatment and rehabilitation as well as after treatment services such as case management to help them to re-integrate into society respectively.

Discussion: The study results indicated that ATS dependence demands a combination of treatment and rehabilitation services. This concern demands long-term planning, designing and training, which should be considered by health service providers. Further studies are needed to determine which treatment or rehabilitation programme may work best for this group of drug-dependent people.

\section{* Corresponding Author: \\ Omid Massah, MD}

Address: Substance Abuse and Dependence Research Centre, University of Social Welfare and Rehabilitation Sciences, Tehran, Iran. Tel: +98 (21) 22180097

E-mail: omchomch@gmail.com 


\section{Introduction}

A

mphetamine-Type Stimulants (ATS) include a group of drugs whose main members are amphetamine and methamphetamine (MA) [1]. However, a range of other substances are in this group, such as ephedrine, pseudoephedrine, methylphenidate and MDMA or 'Ecstasy' an amphetamine-type drug with stimulant properties [2]. ATS dependence is a global and increasing health concern [3]. This is because in recent years, there has been a sharp increase in the production and use of ATS in the world [3]. Over the past three decades, ATS dependence has become the mainstream culture in many countries [4]. Young adults in particular seem to possess a dramatic sense of safety about ATS believing rather largely that the drugs are safe and benign [5]. At the same time, ATS are posing an immediate risk to the health, social and economic aspects of families and societies [6].

Studies have shown no broadly effective pharmacotherapy for treating ATS dependence [7]. Some studies show that methylphenidate, naltrexone, bupropion and mirtazapine are moderately effective for a few subgroups of patients in reducing stimulant use (e.g. patients with less severe dependence), though none has produced an accurate, replicable signal of efficacy $[8,9]$.Therefore, the treatment of ATS dependence is based on psychological treatments such as the Matrix model and brief psychological interventions $[10,11]$.

\section{Methods}

\section{Design and settings}

The current study is part of the first cross-sectional survey of the prevalence of ATS dependence in 22 areas of Tehran, Iran. The present study design was qualitative.

\section{Participants}

Participants were needed to be at least 18 years. Male or female gender was acceptable for the study inclusion. Participants were needed to meet the DSM-IV.TR criteria for ATS dependence [12] at the time of interviewing. Participants were excluded if they were severely intoxicated with ATS or reported severe withdrawal symptoms at the time of interviewing.

\section{Study procedure}

The study was conducted according to the Grounded Theory of Strauss and Corbin [13]. Two trained psychol- ogists interviewed with 35 people with ATS dependence. Interviews were conducted in the sites where participants reported comfort and convenience. To generate data in this qualitative research, semi-structured interviews were applied. Other way included group discussions (i.e. focus groups). Fifteen key informants (i.e. stakeholders) were interviewed in four focus group discussions. The key informants were experts who worked with ATSdependent people in drug treatment services. The focus group technique involved a moderator facilitating group discussions between the selected key informants on the treatment and rehabilitation needs, with hand-scribed data recorded. Key informants included four police officers, four medical doctors, three nurses, two social workers and two psychologists who worked with ATSdependent people.

\section{Ethical considerations}

All participants were individually informed that participation was confidential and voluntary. The study was approved by the United Nations Office on Drugs and Crime in Tehran. Consent form was obtained from all participants.

\section{Data analyses}

Atlas-ti software was used to analyze the qualitative data. The software used the detailed hand coding and labelling. The software did not supplant the interpretive nature of coding but rather aimed at enhancing the efficiency at data retrieval and at using the codes to the data. Coding is an interpretive technique that both organizes the data and provides a means to introduce the interpretations of it into certain quantitative methods [13].

\section{Results}

\section{Baseline characteristics}

In the main survey, 6027 people participated. Overall, 261 of them were ATS-dependent mainly MA. The main routes of ATS administration were smoking (90\%) and ingestion (10\%). In this study, of them, 35 people with ATS dependence were interviewed about their self-perceived treatment needs to be abstinent from ATS. Overall, $87 \%$ were men and $13 \%$ were women. The mean age of the participants was $32(\mathrm{SD}=11)$ years (age range: 18-60 years). The mean year of the schooling was 8 $(\mathrm{SD}=9)$. More than $60 \%$ of the participants were married and lived with their families. More than half of the participants $(54.3 \%)$ were employed at the time of inter- 
Table 1. Baseline characteristics $(n=35)$

\begin{tabular}{ccc}
\hline Demographics & Percent/Mean \\
\hline Mean age (yr) & $35(\mathrm{SD}=11)$ \\
\hline Age range $(\mathrm{yr})$ & $18-60$ \\
\hline Schooling $(\mathrm{yr})$ & Marital status & \\
\hline Currently married & & $22(62.8 \%)$ \\
\hline Currently unmarried & Living status & $13(37.2 \%)$ \\
\hline With family & & $21(60.0 \%)$ \\
\hline Without family & Employment & $14(40.0 \%)$ \\
\hline Employed & & $19(54.3 \%)$ \\
\hline Unemployed & & $16(45.7 \%)$ \\
\hline
\end{tabular}

viewing (Table 1). The quotes have been reported below as emerged in qualitative data analyses.

\section{Rehabilitation not only treatment}

A theme that gradually emerged from the narratives indicated that ATS treatment in Iran demands special attention to not only treatment but long-term rehabilitation. Participants frequently reported that it is not only treatment with some psychological treatments. People with ATS dependence suffered from a range of other problems such as poor mental health, familial problems and lack of employment which needed to be considered for rehabilitation. Interviews frequently highlighted that a combination of rehabilitation and treatment was likely to lead to better success compared with the treatment only.

A 36-year old woman with ATS dependence reported: I need employment. I need to improve my relationships with my family and the society. Psychological treatments are fine but I need rehabilitation too.

A clinical psychologist with nine years of job experience reported: Just psychological treatments are not enough. We also need long-term rehabilitation. People with ATS dependence should receive adequate psychiatric services, family therapy, mental health services and employment services.

\section{Brief psychosocial treatments}

A theme that gradually emerged from the narratives indicated that long-term psychosocial treatments such as the Matrix Model is not completely appropriate for treating
ATS dependence. Interviewees frequently reported that the Matrix Model is long while the provision of psychosocial treatments such as brief psychosocial interventions are costeffective but has been neglected in Iran. Interviewees reported that brief psychosocial treatments in Iran can be more easily accessible than the Matrix Model in drug treatment services. A theme that frequently emerged was to bring treatment guides from other countries and provide brief psychological interventions for treating ATS dependence.

A 33-year old woman with ATS dependence reported: We need brief psychosocial interventions in drug treatment services. Most patients do not like the Matrix Model which is expensive and long.

A medical doctor with eight years of job experience reported: Brief psychosocial interventions can be very accessible in drug treatment services for ATS-dependent patients. But, they have been neglected. We need to do more. We should bring approved treatment guides from other countries and use in Iran.

Family education and engagement in treatment and rehabilitation

Interviews frequently reported that family education was needed about the relapsing nature of ATS dependence. Interviews frequently reported that families of ATS-dependent patients should be engaged in the treatment and rehabilitation procedures. Otherwise, ATS dependence would not be treated. Most Interviewes reported that ATS dependence has a chronic nature should be gradually treated with the collaboration of patients and their families. 
A 38-year old woman with ATS dependence reported: Family education is a must. They should come to treatment and learn about the relapsing nature of ATS dependence. Family should support treatment and rehabilitation. Any struggle with the patient or lack of support can reduce the positive effects of treatment and rehabilitation.

A social worker with six years of job experience reported: Families do not understand ATS-dependent patients. They are always in fight with such patients. We should provide education and encourage them to come to treatment.

\section{After treatment services}

Interviewes frequently reported that ATS treatment is a long-term procedure and needed lifetime treatment and rehabilitation. Providing free and high quality services such as after-treatment mental health, psychiatric and social work services frequently emerged from the interviews. Participants reported that ATS treatment and rehabilitation should be a lifetime responsibility. They reported that after treatment services should be provided for each patient with ATS dependence. But, they reported that this issue has been neglected in Iran. After treatment services such as case management were reported to help them to re-integrate into society.

A 37-year old woman with ATS dependence reported: ATS treatment cannot be limited to treatment only. We need long-term after treatment services to treat ATS dependence. Every patient should be individually followed to feel integrated into society.

A registered nurse with ten years of job experience reported: After treatment services are needed for ATSdependent patients. ATS dependence is a chronic health condition which needs long-term psychiatric, psychological and social work services.

\section{Discussion}

To our knowledge, this is the first study of the treatment and rehabilitation needs of people with ATS dependence. The study indicated that patients with ATS dependence needed long-term rehabilitation. This is consistent with a study which indicated that Iranian patients with ATS dependence need long-term treatment and rehabilitation to experience recovery [14]. Health policy makers in Iran should consider the provision of treatment and long-term rehabilitation programmes for patients with ATS dependence. Drug treatment services in Iran should be equipped to provide both treatment and rehabilitation for ATS dependence.
Brief psychosocial treatments were other suggested interventions for patients with ATS dependence. Studies in other countries show that short-term psychosocial treatments can treat ATS dependence and improve psychological well-being $[15,16]$. A recent study in Iran indicated that long-term psychological treatments such as the Matrix model are long and time-consuming [17]. Furthermore, such treatments are not cost-effective for many patients with ATS dependence $[17,18]$. Brief psychosocial treatments may be easily provided for this group of patients in drug treatment services. Such treatments are likely to be cost-effective and be as effective as long-term psychological treatments for ATS dependence. Further studies are suggested in Iran to evaluate the effectiveness of brief psychological treatments for ATS-dependent patients. Such studies should be based on standard manualized treatment guides.

Family education and engagement in treatment and rehabilitation were other frequently reported needs in this study. Studies indicate that family education and engagement in treatment and rehabilitation can increase social integration and positive treatment outcomes for ATS-dependent patients [19]. Many patients with ATS dependence may not be successful in drug treatment without the participation of their families. Families should be informed about the chronic and relapsing nature of ATS dependence. They should be informed about how to behave with their ATS-dependent family members. Further studies are needed in Iran to evaluate the relationship between family education and engagement in treatment and rehabilitation and long-term recovery from ATS dependence. Drug treatment services should provide family education and engagement in treatment and rehabilitation.

After treatment services were other frequently reported needs in this study. Mental health, psychiatric and social work services were frequently suggested by the Interviewes. Studies indicate that mental health, psychiatric and social work services can contribute to reducing drug use problems [20-22]. Such services may extend the long-term effectiveness of treatment for ATS dependence and facilitate the recovery and rehabilitation procedures. Further studies are need to assess the relationship between providing after treatment services and recovery from ATS dependence.

The current study has several limitations which warrant discussion. First the study was limited to a group of ATS-dependent patients in Tehran. Therefore, the study results may not be generalizable to all ATS-dependent patients in different parts of Iran. The study was limit- 
ed to a qualitative research. Further studies with larger number of samples are needed to investigate the treatment and rehabilitation needs of patients with ATS dependence in different parts of Iran.

\section{Conclusion}

The results of this study highlight the importance of providing both treatment and long-term rehabilitation services for ATS dependence in Iran. As the first report from Western Asia, especially the Persian Gulf region, the findings of this study highlight the necessity of developing special programmes for considering all needs of people with ATS dependence. This could facilitate the process of recovery and rehabilitation among this group of illicit drug-dependents.

\section{Acknowledgments}

The authors would like to thank all people who participated in this study. The authors also thank the United Nations Office on Drugs and Crime in Tehran for financial supporting this study.

\section{Conflict of Interest}

The authors declared no conflicts of interest.

\section{References}

[1] United Nations Office on Drugs and Crime. World drug report. Vienna: United Nations Publications; 2014.

[2] United Nations Office on Drugs and Crime. World drug report. Vienna: United Nations Publications; 2013.

[3] Degenhardt L, Baxter AJ, Lee YY, Hall W, Sara GE, Johns N, et al. The global epidemiology and burden of psychostimulant dependence: Findings from the Global Burden of Disease Study 2010. Drug and Alcohol Dependence. 2014; 137:36-47. doi: 10.1016/j.drugalcdep.2013.12.025

[4] Degenhardt L, Mathers B, Guarinieri M, Panda S, Phillips B, Strathdee SA, et al. Meth/amphetamine use and associated HIV: Implications for global policy and public health. International Journal of Drug Policy. 2010; 21(5):347-58. doi: 10.1016/j.drugpo.2009.11.007

[5] Mehrjerdi ZA. Crystal in Iran: Methamphetamine or heroin kerack. DARU Journal of Pharmaceutical Sciences. 2013; 21(1):22. doi: 10.1186/2008-2231-21-22

[6] Alam Mehrjerdi Z, Mokri A, Dolan K. Methamphetamine use and treatment in Iran: A systematic review from the most populated Persian Gulf country. Asian Journal of Psychiatry. 2015; 16:17-25. doi: 10.1016/j.ajp.2015.05.036
[7] Brensilver M, Heinzerling KG, Shoptaw S. Pharmacotherapy of amphetamine type stimulant dependence: An update Drug and Alcohol Review. 2013; 32(5):449-60. doi: 10.1111/ dar.12048

[8] Phillips KA, Epstein DH, Preston KL. Psychostimulant addiction treatment. Neuropharmacology. 2014; 87:150-60. doi: 10.1016/j.neuropharm.2014.04.002

[9] Alam Mehrjerdi Z, Abarashi Z, Mansoori S, Deylamizadeh A, Salehi Fadardi J, Noroozi A, et al. Methamphetamine use among Iranian heroin kerack-dependent women: Implications for treatment. International Journal of High Risk Behaviors and Addiction. 2013; 2(1):15-21. doi: 10.5812/ijhrba.10216

[10] Alam Mehrjerdi Z, Abarashi Z, Noroozi A, Arshad L, Zarghami M. Correlates of shared methamphetamine injection among methamphetamine injecting treatment seekers: The first report from Iran. International Journal of STD \& AIDS . 2013; 25(6):420-7. doi: 10.1177/0956462413512806

[11] Rawson RA, Huber A, McCann M, Shoptaw S, Farabee D, Reiber $\mathrm{C}$, et al. A comparison of contingency management and cognitive behavioral approaches during methadone maintenance treatment for cocaine dependence. Archives of General Psychiatry. 2002; 59(9):817. doi: 10.1001/archpsyc.59.9.817

[12] American Psychiatric Association. Diagnostic and statistical manual of mental disorders (DSM-5®). New York: American Psychiatric Pub; 2013.

[13] Strauss A, Corbin J. Basics of qualitative research techniques. California: Sage Publications; 1998.

[14] Noori R, Daneshmand R, Farhoudian A, Ghaderi S, Aryanfard S, Moradi A. Amphetamine type stimulants in a group of adults in Tehran, Iran: a rapid situation assessment in twentytwo districts. Iranian Journal of Psychiatry and Behavioural Sciences. 2016; 10(4):e7704. doi: 10.17795/ijpbs-7704

[15] Baker A, Boggs TG, Lewin TJ. Randomized controlled trial of brief cognitive behavioural interventions among regular users of amphetamine. Addiction. 2001; 96(9):1279-87. doi 10.1046/j.1360-0443.2001.96912797.x

[16] Baker A, Lee NK, Claire M, Lewin TJ, Grant T, Pohlman $S$, et al. Brief cognitive behavioural interventions for regular amphetamine users: A step in the right direction. Addiction. 2005; 100(3):367-78. doi: 10.1111/j.1360-0443.2005.01002.x

[17] Massah O, Effatpanah M, Shishehgar S. Matrix model for methamphetamine dependence among Iranian female methadone patients: The first report from the most populated Persian Gulf country. Iranian Rehabilitation Journal. 2017; 15(3):193-8

[18] Sami S, Effatpanah M, Moradi A, Massah O. Matrix model as an intensive rehabilitation in three methadone services in Iran. Iranian Rehabilitation Journal. 2017; 15(3):293-8.

[19] Noori R, Massah O, Moazen B, Farhoudian A, Daneshmand R, Aryanfard S. Women only therapeutic community program and treatment needs in Iran: The first study from the most populated Persian Gulf country. Iranian Journal of Psychiatry and Behavioural Sciences. 2017; 11(2): e9273. doi: 10.5812/ijpbs. 9273

[20] Hill R. Evidence based practices for treatment of methamphetamine dependency: A review. Guelph: Community Engaged Scholarship Institute; 2015. 
[21] Rawson RA, Shoptaw SJ, Obert JL, McCann MJ, Hasson AL, Marinelli Casey PJ, et al. An intensive outpatient approach for cocaine abuse treatment. Journal of Substance Abuse Treatment. 1995; 12(2):117-27. doi: 10.1016/0740-5472(94)00080-b

[22] Huber A, Ling W, Shoptaw S, Gulati V, Brethen P, Rawson R. Integrating treatments for methamphetamine abuse: A psychosocial perspective. Journal of Addictive Diseases. 1997; 16(4):41-50. Doi: 10.1080/10550889709511142 